\title{
A NEW CLASS OF MULTIVALENTLY ANALYTIC FUNCTIONS ASSOCIATED WITH FRACTIONAL $q$-CALCULUS OPERATORS
}

\author{
SUNIL DUTT PUROHIT
}

Abstract. Making use of a certain operator of fractional $q$-derivative, we introduce a new class of multivalently analytic functions in the open unit disk. Among the results investigated for this class of functions include the coefficient inequalities and some distortion theorems. The results provide $q$-extensions of various known results in the theory of analytic functions. Special cases of the results are also pointed out in the concluding section of this paper.

Mathematics subject classification (2010): Primary 30C45; Secondary 26A33, 33D15..

Keywords and phrases: Analytic functions, $p$-valent functions, fractional $q$-calculus operators, coefficient bounds and distortion theorems..

\section{REFERENCES}

[1] M.H. Abu-Risha, M.H. Annaby, M.E.H. Ismail, And Z.S. Mansour, Linear q-difference equations, Z. Anal. Anwend. 26 (2007), 481-494.

[2] G. Bangerezako, Variational calculus on q-nonuniform lattices, J. Math. Anal. Appl. 306, 1 (2005), 161-179.

[3] G. Gasper, And M. Rahman, Basic Hypergeometric Series, Cambridge University Press, Cambridge, 1990.

[4] Z.S.I. MANSOUR, Linear sequential q-difference equations of fractional order, Fract. Calc. Appl. Anal. 12, 2 (2009), 159-178.

[5] I. Podlubny, Fractional Differential Equations (An Introduction to Fractional Derivatives, Fractional Differential Equations, Some Methods of Their Solution and Some of Their Applications), Academic Press, San Diego-Boston-New York-London-Tokyo-Toronto, 1999.

[6] S. OwA, On certain subclasses of p-valent functions, J. Korean Math. Soc. 20 (1983), 41-58.

[7] S.D. Purohit, AND R.K. Raina, Certain subclass of analytic functions associated with fractional q-calculus operators, Math. Scand. 109 (2011), 55-70.

[8] P.M. Rajković, S.D. Marinković, AND M.S. Stanković, Fractional integrals and derivatives in q-calculus, Appl. Anal. Discrete Math. 1 (2007), 311-323.

[9] H.M. SRIVASTAVA, AND M.K. AOUF, A certain fractional derivative operator and its applications to a new class of analytic and multivalent functions with negative coefficients, J. Math. Anal. Appl. 171, 1 (1992), 1-13.

[10] H.M. SRIVastava, And S. Owa, Editors, Current Topics in Analytic Function Theory, World Scientific Publishing Company, Singapore, New Jersey, London and Hongkong, 1992. 